\title{
Six-Minute Walk Test and its Correlation with Spirometry in Stable COPD Patients
}

\author{
B. Sai Krishna ${ }^{1}$ Amrut Kumar Mohapatra ${ }^{1}$ Debasis Behera ${ }^{1}$ Suman Kumar Jagaty ${ }^{1}$ \\ Saswat Subhankar ${ }^{1}$ Rajesh Venkataram² ${ }^{2}$ D. P. Dash ${ }^{1}$
}

${ }^{1}$ Department of Respiratory Medicine, Kalinga Institute of Medical Sciences, KIIT Deemed-to-be-University, Bhubaneswar, Odisha, India

${ }^{2}$ Department of Respiratory Medicine, K.S. Hegde Medical College,

Mangalore, Karnataka, India

J Health Allied Sci ${ }^{\mathrm{NU}}$ 2022;12:280-285.
Address for correspondence Saswat Subhankar, MD, Department of Respiratory Medicine, Kalinga Institute of Medical Sciences, KIIT Deemed-to-be University, Bhubaneswar 751024, Odisha, India (e-mail: saswat.kmc04@gmail.com).

\begin{abstract}
Keywords

- COPD

- $6 \mathrm{MWT}$

- 6MWD

- spirometry

Objectives An impaired exercise tolerance, the main feature in chronic obstructive pulmonary disease (COPD), occurs due to multiple factors. The 6-minute walk test (6MWT) is easy to perform, well-tolerated, and more reflective of activities of daily living. The facility of spirometry is unavailable in many areas of India, where 6MWT can be done easily. This study aims to compare the six-minute walk distance (6MWD) with various demographic, clinical, and spirometry parameters.

Materials and Methods A total of 118 consecutive stable COPD patients fitting the criteria were included in the study. Spirometry was performed in these patients before and after giving a short-acting bronchodilator. 6MWT was performed according to the ATS guidelines. All patients underwent the 6MWT after 10 minutes of spirometry. Statistical analysis was done using GraphPad calculator and SPSS 24.0.

Statistical Analysis All data were clubbed together in a single Excel chart. Statistical analysis was done using SPSS 24.0. Descriptive data are presented as mean \pm standard deviation (SD). Qualitative data are presented as a percentage. Analysis of variance (ANOVA) was used to compare between means. The linear regression model was used to compare between variables. A p-value less than 0.05 was considered significant.

Results The majority of the patients were $>60$ years of age (mean age $=62.99 \pm 6.68$ years) and comprised males and females in the ratio 5.9:1. Smoking was determined to be the most important predisposing factor for the development of COPD. There was a significant negative correlation between 6MWD, age, and smoking index $(p=0.0075$ and 0.0295 respectively). The 6MWD showed a significant positive correlation with FEV1 (in liters), FEV1 (\%), FVC (in liters), and FVC (\%). The 6MWD (meters) and \% predicted $6 \mathrm{MWD}$ showed a significant negative correlation with a drop in $\mathrm{SpO}_{2}$ after the 6MWT ( $r=-0.36 ; p=0.000769, r=-0.3 ; p=0.004$, respectively).

Conclusion 6MWT can be used in cases of COPD where spirometry is unavailable as it correlates significantly with various parameters of the latter.
\end{abstract}

published online

December 30, 2021
DOI https://doi.org/ $10.1055 / \mathrm{s}-0041-1740331$ ISSN 2582-4287.

\footnotetext{
(c) 2021. Nitte (Deemed to be University). All rights reserved.

This is an open access article published by Thieme under the terms of the Creative Commons Attribution-NonDerivative-NonCommercial-License, permitting copying and reproduction so long as the original work is given appropriate credit. Contents may not be used for commercial purposes, or adapted, remixed, transformed or built upon. (https://creativecommons.org/ licenses/by-nc-nd/4.0/) Thieme Medical and Scientific Publishers Pvt. Ltd., A-12, 2nd Floor, Sector 2, Noida-201301 UP, India
} 


\section{Introduction}

Chronic obstructive pulmonary disease (COPD) is one of the leading causes of death in the world, representing an important public health challenge. ${ }^{1}$ It is a major cause of chronic morbidity and mortality throughout the world and many people suffer from this disease for years and die prematurely from it and its complications.

Impaired exercise tolerance is the main feature in COPD that occurs because of hypoxia in the peripheral muscles and several other factors such as increased systemic inflammation, cardiovascular diseases, weight loss, loss of fat-free mass combined with muscle dysfunction, osteoporosis, hypoxemia, and depression., ${ }^{2,3}$ Although the Global Initiative for Lung Diseases (GOLD) international guidelines recommend spirometry as the gold standard for accurate and repeatable measurement of lung function, its role has been debated for the objective evaluation of functional exercise capacity.

A recent review of functional walking tests has concluded that the six-minute walk test (6MWT) is easy to perform, better tolerated, and more reflective of activities of daily living than the other walk tests. ${ }^{4}$ It is a simple test that requires a $100-\mathrm{ft}$ hallway and no exercise equipment or advanced training for technicians. This test measures the distance that a patient can walk on a hard, flat surface in a period of 6 minutes (6MWD). It evaluates the combined responses of all systems involved during exercise, including the pulmonary and cardiovascular systems, systemic circulation, peripheral circulation, blood, neuromuscular units, and muscle metabolism. The self-paced 6MWT assesses the submaximal level of functional capacity. The purpose of the $6 \mathrm{MWT}$ is to evaluate exercise tolerance, monitor therapy, and predict prognosis in patients with chronic respiratory diseases such as COPD, interstitial lung disease (ILD), pulmonary hypertension $(\mathrm{PH})$, and chronic heart failure. ${ }^{5-8}$

The facility of spirometry is not available in many rural areas of India because of the lack of infrastructure where 6MWT can be done easily. Therefore, in this study, we aimed to correlate 6MWD with different demographic, clinical, and spirometric indices, and thus to evaluate whether 6MWT can be used to assess the severity of COPD.

\section{Materials and Methods}

\section{Study Design}

The study was conducted in the Department of Respiratory Medicine, Kalinga Institute of Medical Sciences, Bhubaneswar as a cross-sectional observation study during the period October 2017 and March 2019.

\section{Inclusion criteria}

1. Stable patients with mild-to-severe COPD with no acute exacerbation for the past 6 weeks and not in need of continuous rescue bronchodilators.

2. Age 40 to 70 years.

3. COPD patients with baseline $\mathrm{SpO}_{2} \geq 90 \%$.

\section{Exclusion Criteria}

1. Patients with a history or clinical evidence of pulmonary disease other than COPD.

2. COPD patients with a resting heart rate of more than 120 beats per minute, systolic blood pressure of more than $180 \mathrm{~mm} \mathrm{Hg}$, and/or diastolic blood pressure of more than $100 \mathrm{~mm} \mathrm{Hg}$.

3. COPD patients with co-morbidities such as pulmonary hypertension, obstructive sleep apnea, central sleep apnea, cardiovascular disease, a renal disease that lead to hypoxemia.

4. COPD patients with a history of unstable angina or myocardial infarction during the previous 1 month.

5. COPD patients with a comorbid illness that limit their capacity to perform 6MWT.

6. All patients who cannot complete the test.

7. Those who deny consent.

\section{Methodology}

Clinical history was obtained from all patients. Complete physical examination and investigations including hematological and biochemical tests, plain chest radiograph, electrocardiogram, and two-dimensional (2D)-echocardiogram were done. Patients satisfying the inclusion criteria were selected after obtaining informed consent. Spirometry was performed in these patients before and after giving a shortacting bronchodilator (200-400 $\mu \mathrm{g}$ of salbutamol) and spirometry parameters such as pre-FVC, pre-FEV $\mathrm{F}_{1}$, pre- $\mathrm{FEV}_{1}$ / FVC ratio, post-FVC, post-FEV ${ }_{1}$, post-FEV $1 /$ FVC ratio were noted. The study group was categorized as per the GOLD guidelines.

6MWT was performed in a $30-\mathrm{m}$ long and ventilated indoor corridor. $^{9}$ All patients underwent the 6MWT after 10 minutes of spirometry. Predicted six-minute walk distance (6MWD) was calculated as per the Indian reference Eq. (10)

Indian male $=561.022-[2.507 \times$ age $($ years $)]+[1.505 \times$ weight $(\mathrm{kg})]-[0.055 \times$ height $(\mathrm{cm})]$

Indian female $=30.325-[0.809 \times$ age $($ years $)]-[2.074 \times$ weight $(\mathrm{kg})]+[(4.235 \times$ height $(\mathrm{cm})]$.

\section{Statistical Analysis}

All the data were clubbed together in a single Excel chart. Statistical analysis was done using SPSS 24.0. Descriptive data are presented as mean \pm standard deviation (SD). Qualitative data are presented as a percentage. Analysis of variance (ANOVA) was used to compare between means. The linear regression model was used to compare between variables. A $p$-value less than 0.05 was considered significant.

\section{Results}

A total of 118 patients were included in the study. The majority of the patients were $>60$ years of age (mean age $=62.99 \pm 6.68$ years) and comprised males and females in the ratio 5.9:1 (- Fig. 1). Smoking was determined to be the 


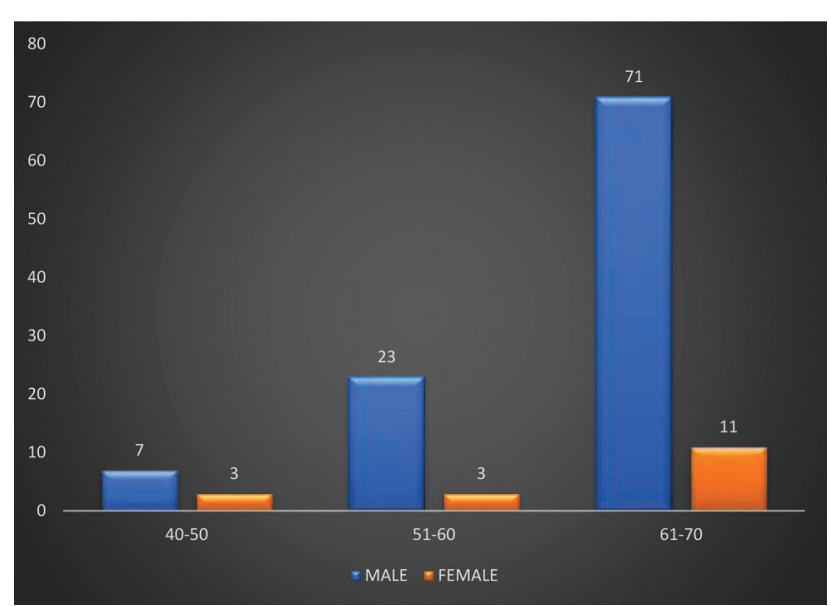

Fig. 1 Age and sex distribution $(N=118)$.

most important predisposing factor for the development of COPD and was present in $70.34 \%$ of the cases.

A greater part of the study group had a normal body mass index (BMI) (53.38\%).

Based on the GOLD 2019 guidelines, the majority of the patients were classified as stage III disease (37.2\%) followed by stage II disease (32.2\%).

Patients with stage I disease had a better exercise tolerance, and our study reported the mean 6MWD to be the highest in this group of patients ( $455.45 \pm 78.57$ meters). The 6MWD was the least in patients with stage IV disease $(f=10.3 ; p<0.0001)$ (-Table 1 ).

The 6MWD was recorded to be the highest in patients with a BMI between 25 and $29.9 \mathrm{~kg} / \mathrm{m}^{2}(400.05 \pm 117.26 \mathrm{~m})$ and least in patients with a BMI $\geq 30 \mathrm{~kg} / \mathrm{m}^{2}(349.67 \pm 57.4 \mathrm{~m})$ $(p=0.23)$.

There was a significant negative correlation between the 6MWD and age and smoking index $(p=0.0075$ and 0.0295 , respectively) in our study. The $6 \mathrm{MWD}$ showed a significant positive correlation with FEV1 (in liters), FEV1 (\%), FVC (in liters) ,and FVC (\%) (-Table 2; -Fig. 2A-D). The 6MWD (meters) and \% predicted 6MWD showed a significant nega- tive correlation with drop in $\mathrm{SpO}_{2}$ after the 6MWT $(r=-0.36$; $p=0.000769, r=-0.3 ; p=0.004$, respectively) (-Table 3 ).

The baseline $\mathrm{SpO}_{2}$ showed a significant positive correlation with 6MWD (meters) and \% predicted of 6MWD. The post 6MWD $\mathrm{SpO}_{2}$ also showed a significant correlation with all the above variables ( - Table 4 ).

\section{Discussion}

COPD is characterized by persistent respiratory symptoms and airflow limitation due to airway and/or alveolar abnormalities usually caused by significant exposure to noxious particles or gases. Age is often listed as a risk factor for COPD. The majority of the patients in our study were $>60$ years of age (mean age $=62.99 \pm 6.68$ years). This could be due to the increased symptoms among patients with aging for which they presented to the hospital. The PLATINO study examined the prevalence of COPD among people $>40$ years of age in five Latin American countries. ${ }^{10}$ The incidence was the highest among patients $>60$ years. Similar reports are available from previous studies as well. ${ }^{11,12} \mathrm{~A}$ higher incidence among males could be attributed to smoking and occupational exposures. The PLATINO study has reported an increased prevalence of COPD among males. ${ }^{10}$ The higher prevalence among men has also been reported in various other studies from India. ${ }^{13,14}$ Although recent data from developed countries has reported that the prevalence of COPD to be almost equal among men and women, negligence, and hesitation of utilizing health care services may lead to under-reporting among females in developing countries such as India.

Cigarette smoking is the leading environmental risk factor for COPD. Cigarette smoke increases oxidative stress and results in chronic inflammation within the airways, leading to obstructive airway disease. Smoking, similar to many previous studies, was determined to be the most important predisposing factor for the development of COPD and was present in $70.34 \%$ of the cases. ${ }^{12,14,15}$

COPD among non-smokers is an emerging entity and has been reported with variable frequency. The disease in this

Table 1 Relation of 6MWD with COPD stage $(N=118)$

\begin{tabular}{|l|l|l|l|l|l|}
\hline Stage & N & Mean 6MWD (meter) & SD & $95 \%$ Cl & \\
\hline I & $11(9.3 \%)$ & 455.45 & 78.57 & $402.67-508.24$ & $P<0.00001$ \\
\hline II & $38(32.2 \%)$ & 426.03 & 72.46 & $402.21-449.84$ \\
\hline III & $44(37.2 \%)$ & 370.43 & 76.74 & $347.10-393.76$ \\
\hline IV & $25(21.18 \%)$ & 344 & 60.74 & $319.21-369.35$ \\
\hline
\end{tabular}

Note: $p<0.05$ is significant.

Table 2 Correlation of 6MWD with other variables

\begin{tabular}{|c|c|c|c|c|c|c|c|}
\hline & Age $(N=118)$ & $\begin{array}{l}\text { Smoking index } \\
(n=83)\end{array}$ & $\mathrm{FEV}_{1 \%}(N=118)$ & $\begin{array}{l}\mathrm{FEV}_{1} \text { (liters) } \\
(N=118)\end{array}$ & $\begin{array}{l}\text { FVC (liters) } \\
(N=118)\end{array}$ & $\begin{array}{l}\text { FVC } \% \\
(N=118)\end{array}$ & $\begin{array}{l}\mathrm{FEV}_{1} / \mathrm{FVC} \\
(N=118)\end{array}$ \\
\hline 6MWD & $\begin{array}{l}r=-0.2452 \\
p=0.0075\end{array}$ & $\begin{array}{l}r=-0.2392 \\
p=\mathbf{0 . 0 2 9 5}\end{array}$ & $\begin{array}{l}r=0.53 \\
p=<0.00001\end{array}$ & $\begin{array}{l}r=0.6022 \\
p=<0.00001\end{array}$ & $\begin{array}{l}r=0.59 \\
p=0.00001\end{array}$ & $\begin{array}{l}r=0.528 \\
p=<0.0001\end{array}$ & $\begin{array}{l}r=0.193 \\
p=0.036\end{array}$ \\
\hline
\end{tabular}

Note: $p<0.05$ is significant. 

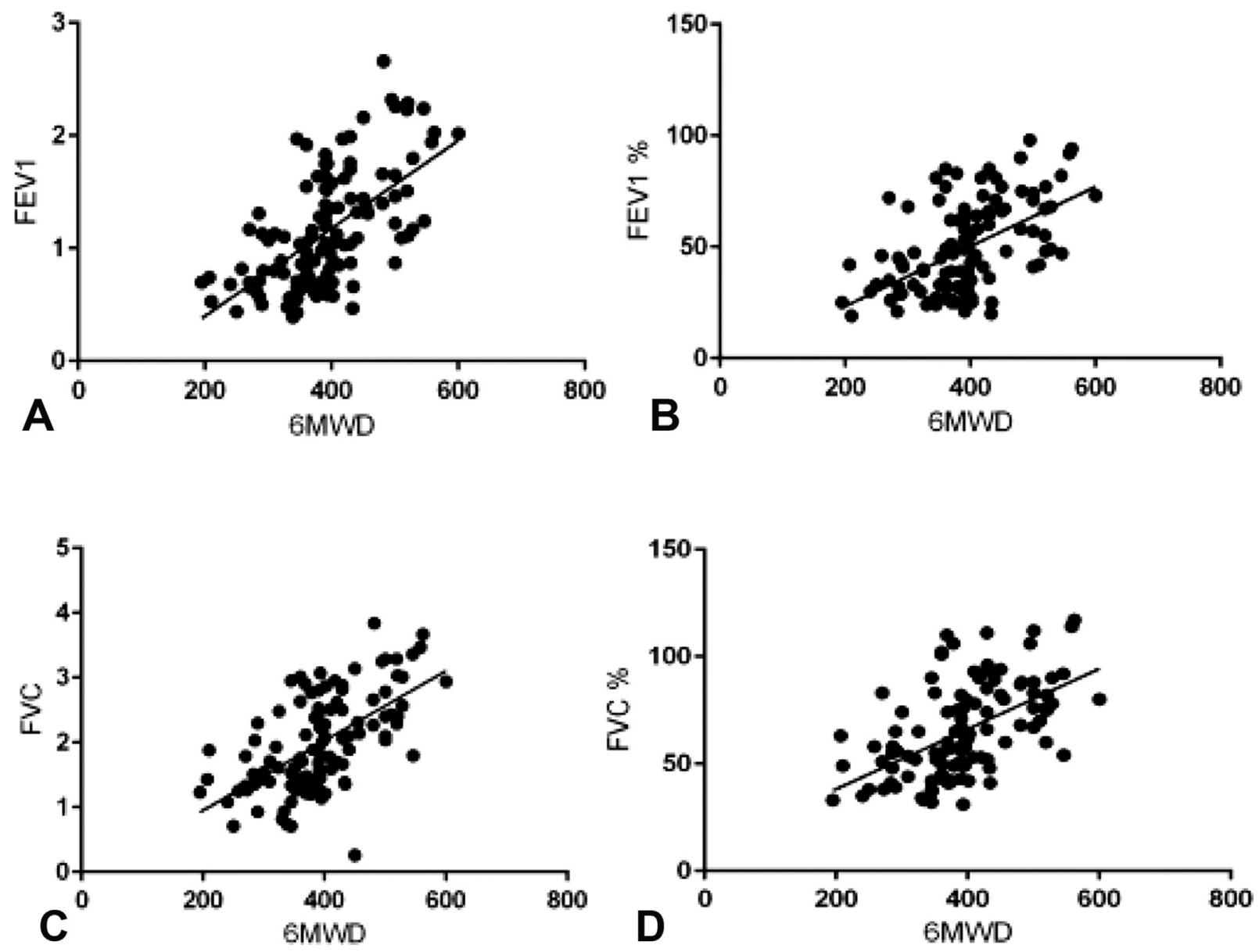

Fig. 2 (A) Linear regression graph between 6MWD and FEV ${ }_{1}$ (liters). (B) Linear regression graph between 6MWD and FEV $1 \%$. (C) Linear regression graph between 6MWD and FVC (liters). (D) Linear regression graph between 6MWD and FVC \%.

Table 3 Correlation of a drop in $\mathrm{SPO}_{2}$ with other variables

\begin{tabular}{|l|l|l|}
\hline & 6MWD & $\begin{array}{l}\text { \% predicted of } \\
\text { 6MWD }\end{array}$ \\
\hline $\begin{array}{l}\text { Desaturation after } \\
\text { 6MWT }(n=83)\end{array}$ & $\begin{array}{l}r=-0.36 \\
p=\mathbf{0 . 0 0 0 7 6 9}\end{array}$ & $\begin{array}{l}r=-0.3102 \\
\mathbf{p}=\mathbf{0 . 0 0 4}\end{array}$ \\
\hline
\end{tabular}

sub-group has been mainly attributed to air pollution. However, other factors such as poorly controlled chronic asthma, occupational exposures to dusts and smokes, and malnutrition should also be considered. ${ }^{16,17}$

A greater part of the study group had a normal BMI (63 [53.38\%]). The $\mathrm{FEV}_{1}$ was calculated to be the least in patients with a $\mathrm{BMI}<18.5 \mathrm{~kg} / \mathrm{m}^{2}$ and the highest in the BMI group of 25 to $29.9 \mathrm{~kg} / \mathrm{m}^{2}$. Low BMI is not only a systemic consequence of COPD but also an indicator of severe disease. The findings in our study can be explained by the fact that most of the patients with a BMI less than $18.5 \mathrm{~kg} / \mathrm{m}^{2}$ had a stage III or IV disease.

The studies correlating BMI and FEV1 in COPD have provided controversial results. ${ }^{18-20}$

Patients with stage I disease have a better exercise tolerance and our study reported the mean 6MWD to be the highest in this group of patients. The 6MWD was the least in
Table 4 Correlation of 6MWD and \% predicted 6MWD with other variables

\begin{tabular}{|l|l|l|}
\hline & $\begin{array}{l}\text { Baseline } \mathrm{SpO}_{2} \\
(N=118)\end{array}$ & $\begin{array}{l}\text { Post 6MWT } \mathrm{SpO}_{2} \\
(\boldsymbol{N}=\mathbf{1 1 8})\end{array}$ \\
\hline $\begin{array}{l}\text { \% predicted } \\
\text { of 6MWD }\end{array}$ & $\begin{array}{l}r=0.193 \\
p=\mathbf{0 . 0 3 6}\end{array}$ & $\begin{array}{l}r=0.3231 \\
\boldsymbol{p}=\mathbf{0 . 0 0 0 3 6}\end{array}$ \\
\hline 6MWD & $r=0.2076$ & $r=0.358$ \\
& $p=\mathbf{0 . 0 2 4}$ & $p=\mathbf{0 . 0 0 0 0 6 9}$ \\
\hline
\end{tabular}

Note: $p<0.05$ is significant.

patients with stage IV disease $(p<0.0001)$. This is in accordance with various other studies. ${ }^{13,14}$

The chronic airflow limitation is characteristic of COPD, which is caused by a mixture of small airway disease (obstructive bronchiolitis) and parenchymal destruction (emphysema). Other than chronic airflow limitation and the multiple pathological changes in the lungs, COPD also causes various significant extrapulmonary changes such as left heart dysfunction and systemic inflammation, which also contribute to the reduction in physical activity in patients with COPD. ${ }^{21}$ Furthermore, in advanced disease, there is loss of fat-free mass, muscle atrophy, and deconditioning of muscle mass leading to peripheral muscle 
weakness which finally results in a reduction in exercise tolerance in patients with COPD. ${ }^{22}$

There was a significant negative correlation between the 6MWD and age and smoking index $(p=0.0075$ and 0.0295 , respectively) in our study. Advancing age and smoking adversely affect the exercise capacity in normal patients as well as in patients with COPD. ${ }^{11,23,24}$

The 6MWD showed a significant positive correlation with FEV1 (in liters), FEV1 (\%), FVC (in liters), and FVC (\%), like many previous studies. ${ }^{11,24,25}$

The 6MWD (meters) and \% predicted 6MWD showed a significant negative correlation with a drop in $\mathrm{SpO} 2$ after the 6MWT $(r=-0.36 ; p=0.000769, r=-0.3 ; p=0.004$ respectively). This could be attributed to the fact that the majority of the patients who had a drop in $\mathrm{SpO}_{2}$ of $>4 \%$ had stage 4 disease.

The baseline $\mathrm{SpO}_{2}$ showed a significant positive correlation with variables such as FEV1 (liters), FVC (liters), 6MWD (meters) and \% predicted of 6MWD. The baseline $\mathrm{SpO}_{2}$ indicates the severity of disease as has been proved in other studies as well. ${ }^{26,27}$ The post-6MWD $\mathrm{SpO}_{2}$ also showed a significant correlation with all the above variables.

\section{Conclusion}

We established a strong positive correlation between 6MWD and FEV1 (liters), FEV1 (\%), FVC (liters), and FVC (\%). The study also showed a significant negative correlation of 6MWD with age, stage of disease, and drop in $\mathrm{SpO}_{2}$ during the procedure $(p<0.05)$. Our study also tried to establish the assessment of approximate FEV1, FVC and FEV1/FVC from the distance walked by the COPD patients in 6MWT and the results were found to be significant for FEV1 and FVC. However, many factors such as age, BMI, and stage of disease were not considered in this assessment.

Spirometry is sometimes difficult to perform and it can be an insensitive tool in assessing the functional status in patients with seriously impaired pulmonary function and extreme dyspnea. 6MWT can be used as an alternative test to spirometry in the assessment of COPD as has been evidenced by our study and supported by several others. It may be used to monitor the changes in pulmonary function in COPD.

\section{Conflict of Interest}

None declared.

\section{References}

1 Halpin DMG, Celli BR, Criner GJ, et al. The GOLD summit on chronic obstructive pulmonary disease in low- and middleincome countries. Int J Tuberc Lung Dis 2019;23(11):1131-1141

2 Di Marco F, Terraneo S, Roggi MA, et al. Physical activity impairment in depressed COPD subjects. Respir Care 2014;59(05): 726-734

3 Watz H, Magnussen H. Komorbiditäten bei COPD. Internist (Berl) 2006;47(09):895-896

4 Solway S, Brooks D, Lacasse Y, Thomas S. A qualitative systematic overview of the measurement properties of functional walk tests used in the cardiorespiratory domain. Chest 2001;119(01): $256-270$
5 Statement ATSATS Committee on Proficiency Standards for Clinical Pulmonary Function Laboratories. ATS statement: guidelines for the six-minute walk test. Am J Respir Crit Care Med 2002;166 (01):111-117

6 Miyamoto S, Nagaya N, Satoh T, et al. Clinical correlates and prognostic significance of six-minute walk test in patients with primary pulmonary hypertension. Comparison with cardiopulmonary exercise testing. Am J Respir Crit Care Med 2000;161(2 Pt 1):487-492

7 Chetta A, Aiello M, Foresi A, et al. Relationship between outcome measures of six-minute walk test and baseline lung function in patients with interstitial lung disease. Sarcoidosis Vasc Diffuse Lung Dis 2001;18(02):170-175

8 Eaton T, Young P, Milne D, Wells AU. Six-minute walk, maximal exercise tests: reproducibility in fibrotic interstitial pneumonia. Am J Respir Crit Care Med 2005;171(10):1150-1157

9 Enright PL, McBurnie MA, Bittner V, et al; Cardiovascular Health Study. The 6-min walk test: a quick measure of functional status in elderly adults. Chest 2003;123(02):387-398

10 Palaniappan Ramanathan R, Chandrasekaran B. Reference equations for 6-min walk test in healthy Indian subjects (25-80 years). Lung India 2014;31(01):35-38

11 Menezes AM, Perez-Padilla R, Jardim JR, et al; PLATINO Team. Chronic obstructive pulmonary disease in five Latin American cities (the PLATINO study): a prevalence study. Lancet 2005;366 (9500):1875-1881

12 Kodavala A. Correlation between forced expiratory volume in first second (FEV1) and 6 minute walk distance in moderate, severe and very severe chronic obstructive pulmonary disease. IOSR J Dent Med Sci 2013;5(02):72-76

13 Thomas B, Sukumaran P. Study to find out the efficacy of 6 minute walk test in assessing response to medical intervention in chronic obstructive pulmonary disease patients. International Journal of Advances in Medicine 2016:538-541

14 Naghshin R, Zaker MM, Afshar AE. Association between six-minute walk test and expiratory spirometry parameters in chronic obstructive pulmonary disease. Indian Heart J 2005;6(03):59-63

15 Grinish T, Khyati S, Mahendra PZ, Bhoomik P. A study of correlation of 6 minutes walk test (6MWT) \& spirometry findings in COPD patients. Int J Res Med. 2017;6(03):12-20

16 Hajare R, Nagarwala R, Shyam A, Sancheti P. Correlation between 6-minute walk distance and spirometry parameters in stable chronic obstructive pulmonary disease patients. International Journal of Research in Medical Sciences 2018;7(01):34

17 Salvi SS, Barnes PJ. Chronic obstructive pulmonary disease in nonsmokers. Lancet 2009;374(9691):733-743

18 Mortimer K, Gordon SB, Jindal SK, Accinelli RA, Balmes J, Martin WJ II. Household air pollution is a major avoidable risk factor for cardiorespiratory disease. Chest 2012;142(05):1308-1315

19 Zhou Y, Wang D, Liu S, et al. The association between BMI and COPD: the results of two population-based studies in Guangzhou, China. COPD 2013;10(05):567-572

20 Shimray A, Singh W, Ningshen K, Kanan W, Devi A, Laishram R. Association body mass index and spirometric lung function in chronic obstructive pulmonary disease (COPD) patients attending RIMS Hospital, Manipur. Journal of Medical Society 2014;28(03):157

21 Wu Z, Yang D, Ge Z, Yan M, Wu N, Liu Y. Body mass index of patients with chronic obstructive pulmonary disease is associated with pulmonary function and exacerbations: a retrospective real world research. J Thorac Dis 2018;10(08):5086-5099

22 Watz H, Waschki B, Boehme C, Claussen M, Meyer T, Magnussen H. Extrapulmonary effects of chronic obstructive pulmonary disease on physical activity: a cross-sectional study. Am J Respir Crit Care Med 2008;177(07):743-751

23 Gosker HR, Engelen MP, van Mameren H, et al. Muscle fiber type IIX atrophy is involved in the loss of fat-free mass in chronic obstructive pulmonary disease. Am J Clin Nutr 2002;76(01): 113-119 
24 Ozalevli S, Ozden A, Gocen Z, Cimrin AH. Comparison of six-minute walking tests conducted with and without supplemental oxygen in patients with chronic obstructive pulmonary disease and exerciseinduced oxygen desaturation. Ann Saudi Med 2007;27(02):94-100

25 Woon WT, Fang WF, Lin MC, Wang YH. Six-minute walking test in patients with chronic obstructive pulmonary disease. Thorac Med 2005;20:431-437
26 Gupta SS, Gothi D, Narula G, Sircar J. Correlation of BMI and oxygen saturation in stable COPD in Northern India. Lung India 2014;31(01):29-34

27 Golpe R, Pérez-de-Llano LA, Méndez-Marote L, Veres-Racamonde A. Prognostic value of walk distance, work, oxygen saturation, and dyspnea during 6-minute walk test in COPD patients. Respir Care 2013;58(08):1329-1334 